\title{
Multimedia and student activity: An interpretive study using VideoSearch
}

\author{
Jan Herrington and Ken Knibb \\ Edith Cowan University
}

\begin{abstract}
The allocation of time to different student activities in formal university settings, has been a subject of interest to researchers in recent years. As part of an interpretive study into how students use interactive multimedia, small groups of students were videotaped using an interactive multimedia program based upon a framework of situated learning. The purpose of the study was to determine whether students spent the major part of their time attending to the program-as some studies suggest this is common in tertiary education settings-or whether they actively participated in the learning process.
\end{abstract}

The data was analysed using VideoSearch, a software program which facilitates analysis of qualitative data by coding excerpts of videotaped material into userdefined categories. The program enables coding from a digitised video source by selecting a segment of the video and attaching a category to it. The findings of the study suggest that an interactive multimedia program based on a situated learning model is conducive to promoting important student activities such as articulation and reflection.

\section{Distribution of time to learning activities}

Anyone who has observed a child playing on Sega/Nintendo or computer game will have noticed that the child has a very active role. Frequently, the child can be seen to weave and duck, to crouch and dodge, and to respond actively, spontaneously and physically while manoeuvring his or her way around the life and death situations. However, there is very little time for the child to think in responding to the various challenges presented by the game environment. Children react rather than consider. For many of these programs, the educational value for the player is inversely proportional to the reaction time required (ASCILITE, 1995).

The pattern of responses of students in a tertiary setting, and the distribution of time spent on various activities as they learn, is vastly 
different to the pattern of the video game player. The allocation of time to different student activities in formal university settings, has been investigated by Laurillard (1996). In a study of the distribution of time devoted to a variety of learning activities, Laurillard investigated the number of hours spent Attending, Practicing, Discussing and Articulating as students studied and attended lectures and tutorials in a regular university course. She found that, typically, Attending was by far the most common activity. As an example, she gave the distribution of activities of a student in an engineering course in a 40 hour study week (Table 1).

Table 1: Distribution of student activities in a 40-hour study week (Laurillard, 1996)

\begin{tabular}{|l|c|c|c|c|}
\hline & Attending & Practising & Discussing & Articulating \\
\hline Lectures & 15 & & & \\
\hline Audio-visual & 1 & & & \\
\hline Tutorials & 3 & & 1 & \\
\hline Practice & & 10 & & \\
\hline Reading & 2 & & & 8 \\
\hline Assignments & & & & 8 \\
\hline TOTAL & 21 & 10 & 1 & $20 \%$ \\
\hline & $52 \%$ & $25 \%$ & $3 \%$ & \\
\hline
\end{tabular}

While these figures appear to allow for enormous latitude-for example, they assume that no discussion occurs in lectures, that no attending occurs in assignments, that no discussion occurs in audio-visual-they indicate that traditional methods of teaching at university emphasise the transmission of knowledge rather than active participation by students in the learning process.

Both of these examples point to severe shortcomings in learning environments: the first, in denying students a reflective role, the second in denying an active role.

\section{The research study}

The study described here sought to investigate the distribution of students' activities as they used an interactive multimedia program on assessment in mathematics for preservice teachers: Investigating assessment strategies in mathematics classrooms (Herrington, Sparrow, Herrington, \& Oliver, 1997; Herrington, Herrington, Sparrow, \& Oliver, 1998). The 
Cognition and Technology Group at Vanderbilt (1992) contend that the learning environments they produce are meant to be explored and discussed at length rather than simply read or watched. Similarly, the interactive multimedia program on assessment was designed to minimise keyboard responses, and maximise thoughtful, active reflection and discussion between the users.

The program had been specifically designed to incorporate a number of characteristics consistent with situated learning (Brown, Collins, \& Duguid, 1989; Collins, Brown, \& Newman, 1989; McLellan, 1996). For example, the program was based upon an authentic context and an authentic and complex activity; it provided multiple perspectives of the issue of assessment; it promoted reflection and articulation of learning; it required students to work in small collaborative groups; and it assumed that coaching and support would be provided by the lecturer or other students.

The task the students were given was a complex and sustained one. It was presented realistically, in authentic looking documents-a memo and a letter-rather than simply a list of possible activities, and it include genuine constraints such as deadlines and time allowances. In the task scenario (see Figure 1), a parent has written to the school, advising that her child becomes very anxious before each mathematics test, and has asked whether her daughter can be assessed in other ways. The letter is accompanied by a memo to 'new teachers' (the students working on the multimedia program) from the Mathematics Coordinator, asking them to observe some assessment strategies in classrooms, talk to teachers and students, consult experts (all of which they can do on the interactive multimedia program) and to prepare a new assessment plan for mathematics in the school. The task assumes that the students would be working in pairs or small groups, and requires them to examine the resource from a variety of perspectives.

When the multimedia program was first used with students and evaluated as part of a larger study, it was noticed that their use of the keyboard was relatively infrequent. Rather than an excessive amount of attending, most of the time appeared to be spent thinking and discussing.

In order to substantiate this observation on the amount of time spent on various activities, one group of students was monitored using the VideoSearch program for a period of exactly 30 minutes, starting approximately 30 minutes into the students' work session of 90 minutes. This was done to allow a short settling in period in order to gauge a more 
typical pattern of use. A 30 minute excerpt was also chosen for pragmatic reasons-this digitised footage fitted neatly onto a GB Jaz disk with sufficient picture quality to readily determine student action and discussion.

\section{Collaborative learning}

All activities are addressed to a group rather than an individual to allow for collaborative learning

\section{Multiple perspectives}

A problem situation is described which requires investigation of the resource from a variety of perspectives

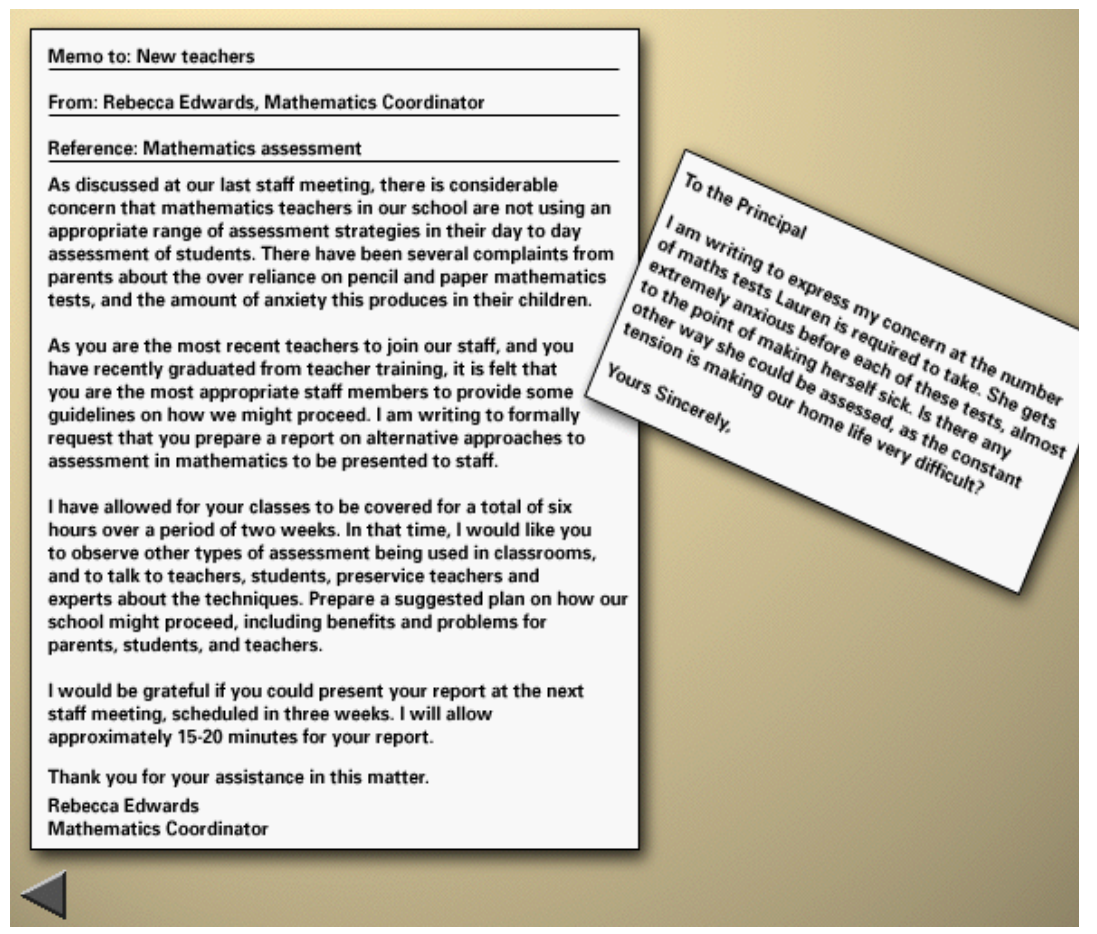

\section{Authentic task}

A realistic task is set, requiring a written response

\section{Articulation}

An opportunity to articulate and defend findings is given, together with a recommended time limit

\section{Authentic context}

A supplementary document is provided, often the source of the problem that requires action

Figure 1: Critical features of the investigations 
The students' actions were timed according to four categories:

1. Attending: Selecting, watching or reading the media elements of the assessment program such as video clips or documents

2. Discussing/reflecting: Discussion between partners or reflective thinking (silence)

3. Typing and composing: Typing into the notebook and formulating what to type

4. Off task: Off-task behaviours.

These categories most closely resembled the observable types of behaviour that were of interest, and were more salient than the categories chosen by Laurillard (1996). Laurillard's distinction between discussion and articulation was particularly problematic given the theoretical framework used in the study which sees no distinction between the two, and where both involve higher processes of formulating thought into speech, as described by Vygotsky: 'Thought undergoes many changes as it turns into speech. It does not merely find expression in speech; it finds reality and form' (cited in Lee, 1985 p. 79).

VideoSearch was used to corroborate observation of the nature of their activities as they used the program, by investigating a sample of the work session to determine the allocation of time devoted to each activity.

\section{VideoSearch}

In the past, if you wanted to analyse precisely any student behaviour of interest, such as time on task, the only option was to take notes about the frequency of such behaviour. More recently, the ability to videotape the event meant that you could replay the tape and record the duration of the behaviour with a stopwatch. More recently still, computer-based qualitative analysis programs such as NUD•IST have meant that you could transcribe the event (if it was verbal), import it into the analysis program and analyse the frequency and types of talk. All of these methods have methodological shortcomings which, depending on your study, could impact upon the accuracy of your findings.

VideoSearch (Knibb, 1997) is a software program which facilitates analysis of qualitative data by coding excerpts of videotaped material into userdefined categories. The program is similar to NUD•IST (Qualitative Solutions \& Research, 1993) in that it enables analysis of qualitative data, 
but where NUD•IST works with text in the form of transcripts, VideoSearch works directly with the video data. The program enables coding from a digitised video source by selecting a segment of the video and attaching a category to it.

Using VideoSearch involves three main processes, (a) digitising the video, (b) coding and labelling the digital video, and (c) analysing and interpreting the coded and labelled segments. The source for the videos can be a VCR, video camera or standard television broadcast signal. The software can be used to capture video signals from any of these sources and store them on computer hard disk as QuickTime ${ }^{\mathrm{TM}}$ movies. Power Macintosh computers with a video capture card installed are required to digitise the movies. As much as ten hours of video can be stored on a nine GB hard drive but the duration depends on the quality and size of the digital video required.

The user initiates the digitising process by clicking the Record button. Digitising is done in real time. The digitising process can be stopped by clicking a Stop button. At this point, the software produces a movie window containing the digitised video and a code window (Figure 2).

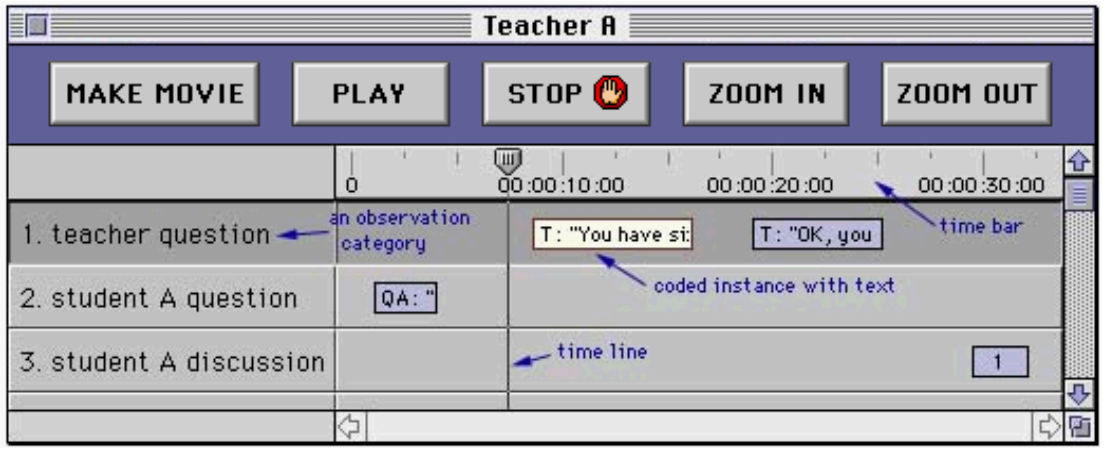

Figure 2: Code window linked to the movie window

VideoSearch can be used to code and label instances of events in time. An almost unlimited number of instances of events can be linked with any segment of the digitised video. Line 1 in Figure 2 shows two instances of the category Teacher question. The time bar in Figure 2 shows the range of times that can be viewed. The time line represents the time currently displayed in the source movie window. New instances can be inserted by holding down the command key, and then clicking and dragging in the time bar. Fine control can be achieved by 'zooming in' on a time segment. 
Instances of events can be played back by double clicking on the representation of the instance in the code window. A movie of the instance appears in a separate window. By clicking on the Make Movie button, all instances of a selected category are placed together in a separate movie and played. For example, if this was done for the first row in Figure 2, all instances of Teacher question would be played back. The process of creating a movie from separate coded instances takes less than 0.5 of a second. Summary statistics, indicating the number of instances in a category and total time that a coded event is represented are also available. About 5000 words can be attached to any instance. This text can subsequently be searched to recall and play labelled video segments. Codes from different categories can be combined and used to produce new movies. For example, a movie could be created of all disruptive behaviours during a lesson and times that the teacher was not facing the class. New movies created can be saved in a format that can be played on Windows or Macintosh computers.

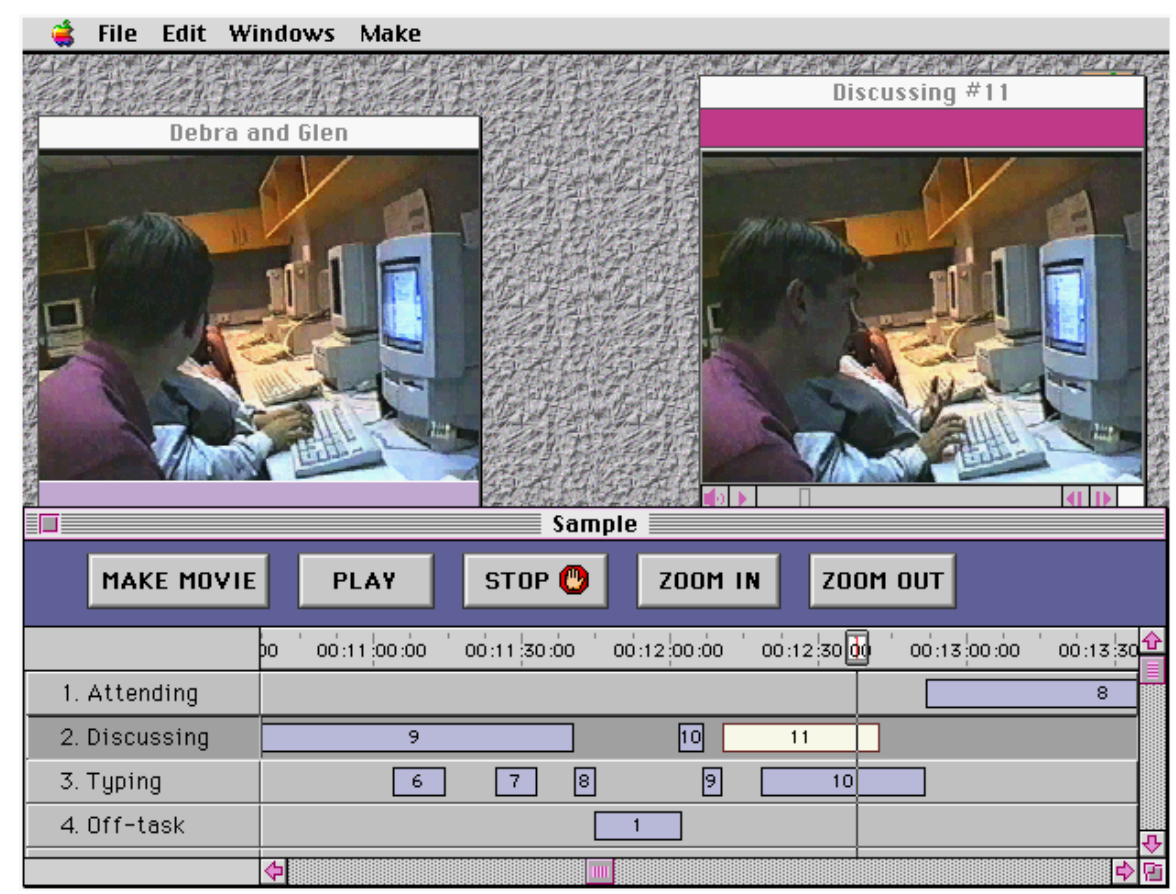

Figure 3: The VideoSearch interface showing the data as coded (bottom), the digitised video source (top left) and a categorised excerpt (top right) 


\section{Research findings}

VideoSearch was particularly appropriate to the analysis of the present study because it allowed analysis of qualitative data by coding excerpts of videotaped material into user-defined categories. No transcripts of verbal data needed to be made, and no timing device was necessary.

Figure 3 shows the coding tool with the four defined categories of activities on the left hand side. The video movie on the left is the digitised video source of 30 minutes of students' use of the multimedia program on assessment. The video clip on the right is the selected video clip, the eleventh occurrence of Discussing.

The VideoSearch software enabled a very precise categorisation of student activity. On occasions, the students engaged in two activities at the same time, for instance, discussing, and typing, where while one student typed the other's talk was on general issues rather than the composition of what to type. On these occasions, the instances of both were recorded, such as excerpt No. 11 of Discussing and excerpt No. 10 of Typing in Figure 3 above. This meant that while 30 minutes was monitored, the total time accounted for was 34 minutes and 3 seconds. Percentage times were calculated from the total of combined activities. The majority of time was spent discussing and reflecting upon the multimedia program and the task, with $20 \%$ spent composing and typing in the electronic notebook. Contrary to other findings in 'traditional' classes, students' attending time was calculated as occupying $33 \%$ of the total time. The times recorded on each of the four nominated categories are provided in Table 2 below.

Table 2: Percentage times spent on student activities while using the assessment program

\begin{tabular}{|l|c|c|c|c|}
\hline & $\begin{array}{c}\text { Attending, } \\
\text { selecting, } \\
\text { watching, reading }\end{array}$ & $\begin{array}{c}\text { Discussing, } \\
\text { reflecting }\end{array}$ & $\begin{array}{c}\text { Composing } \\
\text { and typing in } \\
\text { notebook }\end{array}$ & Off task \\
\hline Total time & $11 \mathrm{~min} 7 \mathrm{sec}$ & $15 \mathrm{~min} 41 \mathrm{sec}$ & $6 \mathrm{~min} 51 \mathrm{sec}$ & $24 \mathrm{sec}$ \\
\hline Percentage & $33 \%$ & $46 \%$ & $20 \%$ & $1 \%$ \\
\hline
\end{tabular}

The figures for this small excerpt suggest that the interactive multimedia program on assessment was conducive to promoting student activities other than attending behaviour. Unlike the traditional university courses mentioned by Laurillard (1996) and McNaught (1996), with their emphasis 
on the transmission mode, the students using the assessment program were able to reflect upon and discuss their learning for a substantial portion of the observed time. Their experience was not comparable to the student attending in a formal lecture, nor the child reacting spontaneously to a video game. The students attended to the video and text elements provided by the program, and consolidated this information with thoughtful discussion and creativity in the preparation of a written response.

It could be suggested that several factors contributed to the facility of the learning environment to promote a strong proportion of articulation and reflection during students' time as they worked on the interactive multimedia program. The learning environment may have been successful in this because it provided an ill-defined, open-ended and complex task with no simplification of procedures, which required written and oral responses. In the completion of the task, students were able to explore a large number of resources to enable sustained examination from a number of different perspectives with the necessity to define the tasks and subtasks required to complete the activity. Non-linear navigation enabled ready access to any media element in a non-sequential order, and students were able to return to any element of the program if desired, and to act upon reflection.

Collaborative groupings of students as they used the program enabled reflection with aware attention. The program allowed students to reflect upon their own experiences and to compare them with those of experienced classroom teachers, mathematics education experts and preservice teachers in the third year of their teacher training course. Most importantly, the learning environment provided a complex task incorporating inherent, as opposed to constructed, opportunities to articulate. The complexity of the investigation afforded a necessity to articulate to complete the task, rather than in response to cues built into the program.

Software used collaboratively in a situated learning environment does not require frequent keyboard and mouse use. Rather, the emphasis is on reflective responses that contribute to the creation of an authentic product such as a report, and where each participant provides a unique function or role to the task.

Students using the assessment program based on situated learning devoted a substantial portion of their time to discussion and reflection rather than excessive attending to content. Such a finding inevitably 
prompts the need for further research, both systemic and analytic (Salomon, 1991). For example, would students spend a greater proportion of time attending to a linear multimedia format than they did, in this instance, to a complex, referential program? Does the theoretical basis for the design of interactive multimedia influence the proportion of time spent by students on activities such as attending, reflecting, and discussing?

Further research is needed to establish precisely the design elements of interactive multimedia which enable reflection and articulation to occur as a paramount consideration rather than a chance event. This paper has described some insights gained from the analysis of one small sample of student activity. The advent of VideoSearch, a powerful analysis tool for video data, will enable further research opportunities in the investigation of the way students learn from multimedia.

\section{References}

ASCILITE (1995, December). Games forum. Paper presented at the Twelfth Annual Conference of the Australian Society for Computers in Learning in Tertiary Education. Melbourne, Victoria.

Brown, J.S., Collins, A., \& Duguid, P. (1989). Situated cognition and the culture of learning. Educational Researcher, 18(1), 32-42.

Cognition and Technology Group at Vanderbilt (1992). An anchored instruction approach to cognitive skills acquisition and intelligent tutoring. In J.W. Regian \& V.J. Shute (Eds.), Cognitive approaches to automated instruction (pp. 135-170). Hillsdale, NJ: Lawrence Erlbaum Associates.

Collins, A., Brown, J.S., \& Newman, S.E. (1989). Cognitive apprenticeship: Teaching the crafts of reading, writing, and mathematics. In L.B. Resnick (Ed.), Knowing, learning and instruction: Essays in honour of Robert Glaser (pp. 453-494). Hillsdale, NJ: LEA.

Herrington, A., Herrington, J., Sparrow, L., \& Oliver, R. (1998). Learning to teach and assess mathematics using multimedia: A teacher development project. Journal of Mathematics Teacher Education, 1(1), 89-112.

Herrington, A.J., Sparrow, R.L., Herrington, J., \& Oliver, R.G. (1997). Investigating assessment strategies in mathematics classrooms [Book and CD-ROM]. Perth: MASTEC, Edith Cowan University.

Knibb, K. (1997). VideoSearch [Computer software]. Perth: Edith Cowan University. 
Laurillard, D. (1996). The changing university. [On-line]. Available: ITFORUM@UGA.CC.UGA.EDU.

Lee, B. (1985). Intellectual origins of Vygotsky's semiotic analysis. In J.V. Wertsch (Ed.), Culture, communication and cognition: Vygotskian perspectives (pp. 66-93). Cambridge: Cambridge University Press.

McLellan, H. (Ed.). (1996). Situated learning perspectives. Englewood Cliffs, NJ: Educational Technology Publications.

McNaught, C. (1996, June). The nature of information technology and its implications for practices and policy in higher education. Paper presented at The Role of

Information Technology in Education Development in the Asia Pacific Region: ASAIHL Conference. Melbourne, Australia.

Qualitative Solutions \& Research (1993). NUD•IST [Computer software]. Melbourne: Author.

Salomon, G. (1991). Transcending the qualitative-quantitative debate: The analytic and systemic approaches to educational research. Educational Researcher, 20(6), 10-18.

Dr. Jan Herrington

Senior Instructional Designer

Edith Cowan University

Pearson St, Churchlands, 6018

Western Australia.

j.herrington@cowan.edu.au 